group. The "divisional" type of organization was not in fact new and had been in operation in some specialties in several areas for some time. This was also true of socalled medical auditing.

Dr. P. MAcArthur (N.E. Region) doubted whether the divisional organization could be introduced voluntarily, and argued in favour of divisional chairmen being appointed by regional boards from amung the senior clinicians, as proposed by the English working party. The appointment should be for five years. Mr. W. M. FARQUHARSON-LANG (N.E. Regional Board and chairman of the Departmental Committee on Hospital Administration) thought the proposed organization could lead to improvement in the medical advisory arrangements for hospital boards. It would be necessary to provide effective administrative support for the chairmen of divisions and for the committee of chairmen. In reply to Dr. W. P. U. KenNedy (S.E. Regional Hospital Junior Staff Group) Dr. Brotherston said the place of junior staff within the organization had not been forgotten in the deliberations, but would need more discussion " on the ground." Other matters raised by speakers included the financing of effective medical auditing and the role of medical superintendents under the scheme.

Dr. C. W. Clayson (Western Region and Joint Working Party), introducing Chapter II on medical staffing, said the Working Party had recognized at an early stage that the basis of any discussion on staffing problems must be the existence of a chronic shortage of doctors. In spite of an increase over the past dozen years of $30 \%$ in senior and nearly $60 \%$ in junior staff, there was still a serious shortage. The numbers in general practice meanwhile were actually falling. The factors creating this situation would continue to operate, and hence there was a need to relieve medical staff as much as possible of nonmedical duties by providing them with technical and secretarial assistance, and for delegation by consultants of duties which could be undertaken by appropriate intermediate staff. The Working Party had concluded that one paramount need was to foster reintegration of hospital and general practice, which would be to the benefit of both.

Other sources of staff were part-time employment in hospital of local authority doctors engaged in specialist preventive work in the paediatric, geriatric, and mental health fields; married women doctors ; and retired doctors. This would mean a substantial expansion of the medical assistant grade, with a compensatory reduction in the registrar establishment-which would be desirable in the interests of a better balance between staffing and training needs.

Dr. JoHN SmITH (Scottish Home and Health Department) felt that the association of general practitioners with the hospital was most important. A recent survey had shown that there were twice as many aspirants to a hospital career as there were likely vacancies, whereas only half the number needed for general practice wished to enter it. $\mathrm{He}$ felt sure that many in both groups would be well content with a career that combined the two. The combined local authority and hospital appointment would also be attractive to many.
Dr. A. Allison (Western Region) and two other speakers expressed concern about the proposed expansion of the medical assistant grade. This might lead to a recurrence of the old senior hospital medical officer problem. Dr. Clayson did not think this likely under the new organization, though there might be problems in connexion with delegated responsibility.

\section{Use of Beds}

Mr. A. H. Jacobs (Western Region and Joint Working Party), introducing Chapter III-Alternatives to Traditional Systems of Hospital Care-said the Working Party were concerned to know whether the present system of admission to and treatment in hospital provided both the best and most economic use of hospital beds. They had reached the conclusion that several changes could usefully be made-including planned admission to hospital (with separation of the emergency and waiting-list cases); development of selective patient grouping according to clinical need; and the allocation of beds to provide this flexibility. Several categories could be distinguished, such as routine acute care beds (including intensive nursing care beds) ; intensive therapy beds ; and short-stay beds, perhaps divided into overnight and observation beds, and five-day beds.

Dr. Mackay Hart (Western Region and Joint Working Party) said building changes would be needed to put many of these ideas into effect, but quite a lot of them could be realized without this. Dr. ERIC SAMUEL (S.E. Region) thought there was room for better planning of radiological, laboratory, and other investigations of inpatients. Several speakers suggested, and $\mathrm{Mr}$. JACOBS agreed, that a great deal more information would be needed before many of these changes could be approved and adopted.

Mr. N. G. C. Hendry (N.E. Region and Joint Working Party), in introducing Chapter IV on Operational Research, discussed the techniques involved and their application to medical work generally and hospital work in particular. These covered such things as routine statistics, assessment of standards of care, and work study. The cynic, he said, might argue that people could spend so much time investigating the work they were doing that they ended up doing no work at all. The Working Party were convinced that great benefit could come from intelligent use of these methods, and they recommended further strengthening of the Health Department's Research and Intelligence Unit.

\section{"Communications"}

Mr. E. U. E. Elliott-Binns (Scottish Home and Health Department) spoke briefly to Chapter $\mathrm{V}$ on Communications, pointing out that the term " communications" was not altogether satisfactory, but it was difficult to find a more suitable one. It was concerned essentially with ways and means of getting information to those for whom it was necessary or useful. He drew the attention of the conference to two of the Working Party's proposals-namely, the establishment of some kind of " staff college," which would be concerned with the study of and training in management, and the appointment of a small standing committee representative of the various interests to devise and keep under review the channels of communication within the service.

In closing the meeting Dr. Hamilton said that the Department hoped very much that the report and its recommendations and proposals would be thoroughly and critically discussed by doctors and others all over the country.

\section{NEW APPLIANCES \\ Prototype Cryosurgical Probe}

Mr. P. McKelvie, Institute of Laryngology and Otology, London, and $\mathrm{Mr}$. O. $\mathrm{H}$. Shabeen, Guy's Hospital, London, write: This prototype cryosurgical probe is $15 \mathrm{~cm}$. long, the low temperature tip being 1.5 by $0.5 \mathrm{~cm}$. Operating from a cylinder of carbon dioxide, it reaches minus $40^{\circ} \mathrm{C}$. in one second and defrosts electrically in eight

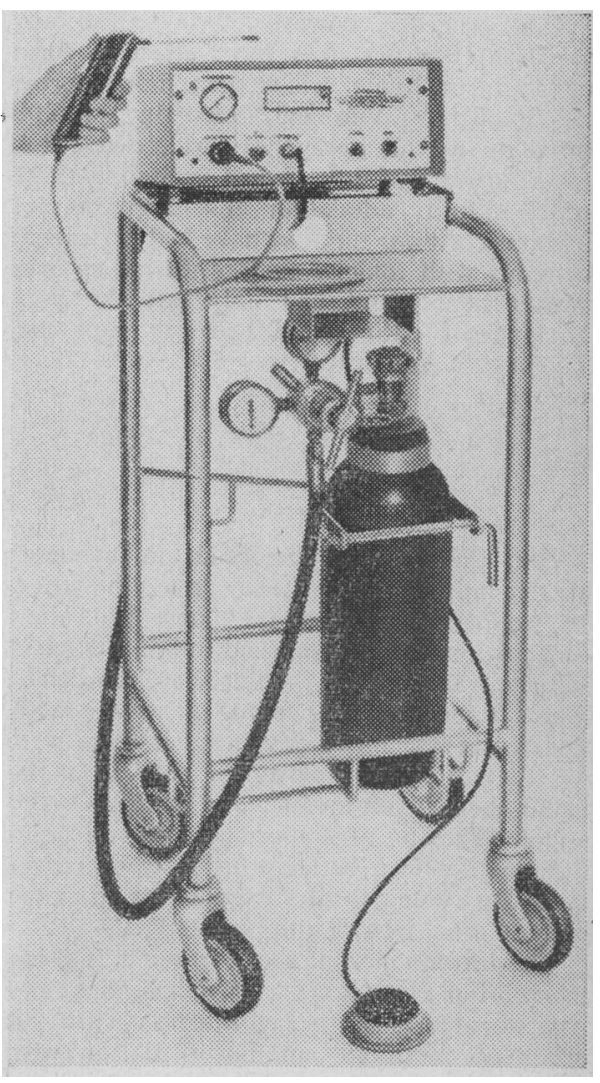

seconds. It is autoclavable, light, and portable, and is particularly suitable for the destruction, with haemostasis, of small lesions accessible in the upper air and food passages, though its general applicability is widespread.

It is manufactured by Spembley Products Ltd. and distributed through Keeler Ltd., London. 